\title{
Arabic: short history, field of usage, and vocabulary entered in the Indonesian language
}

\author{
Sudaryanto*) \\ Universitas Ahmad Dahlan \\ *) Correspondences author: J1. Kapas No.9, Semaki, Umbulharjo, Kota Yogyakarta, \\ Daerah Istimewa Yogyakarta55166, Indonesia; e-mail: sudaryanto82@yahoo.com
}

\begin{abstract}
This essay discusses three fundamental issues about the Arabic language, which is (1) a brief history of the entry of Arabic to the Archipelago, (2) the field of use of the Arabic language, and (3) Arabic vocabulary that goes into Indonesian. At the end of the 15th Century AD, estimated Arabic brought by Arab traders, both derived from Hadramaut and of Persia. The use of Arabic in the field of Indonesian mostly related to religious life (Islam). As for the Arabic vocabulary that goes into Indonesian, among others, akhlak, amal, azab, akhirat, ayat, ilmu, ibadah, infak, insyaf, iman, imam, khilaf, khotbah, kitab, kalam, zaman, dan zina.
\end{abstract}

Keywords: History, Field usage, vocabulary, Arabic, Indonesian.

Article History: Received: 16/03/2017; Revised: 01/04/2017; Accepted: 15/04/2017; Published: 05/05/2017

How to Cite (MLA 7th): Sudaryanto. "Arabic: short history, field of usage, and vocabulary entered in the Indonesian language." Hortatori: Jurnal Pendidikan Bahasa dan Sastra Indonesia 1.1 (2017): 92-97. Print/Online. Copyrights Holder: Sudaryanto. First Publication: Hortatori Jurnal Pendidikan Bahasa dan Sastra Indonesia (2017).

This work is licensed under a Creative Commons Attribution-ShareAlike 4.0 International License.

\section{Pendahuluan}

Bahasa Indonesia yang saat ini berstatus sebagai bahasa resmi negara (Pasal 25 ayat (1) UndangUndang Nomor 24 Tahun 2009) secara historis berasal dari bahasa Melayu. Bahasa Melayu merupakan salah satu dari sekitar tiga ratus bahasa daerah di wilayah kepulauan Nusantara yang semula dipakai oleh para penuturnya di daerah Sumatra (Tadmor, 2007). Pemakaian bahasa Melayu meluas ke seluruh pelosok Nusantara. Meluasnya bahasa Melayu selain disebabkan oleh status bahasa yang pada zaman Kerajaan Sriwijaya sebagai bahasa resmi kerajaan, juga karena jasa para pedagang dan pelaut yang menggunakan bahasa Melayu sebagai alat komunikasi antarsuku, antarbudaya, dan antarpulau. Sejak itu, bahasa Melayu telah menjadi lingua franca.

Salah satu ciri dari bahasa Melayu ialah sangat terbuka dan mudah disesuaikan dengan perkembangan zaman dan pengaruh dari luar. Yang dimaksud dengan pengaruh dari luar, yaitu pengaruh bahasa-bahasa lain yang ikut mempengaruhi perkembangan bahasa Melayu. Di antaranya, bahasa Sanskerta, bahasa Arab, bahasa Belanda, bahasa Inggris, bahasa Cina/Tionghoa, bahasa Jepang, bahasa Portugis, bahasa Hindi, bahasa Tamil, bahasa Persia, dan bahasa-bahasa daerah di Indonesia. Dalam konteks tulisan ini, saya hanya mengambil bahasa Arab sebagai objek pengamatan terkait sejarah masuknya bahasa Arab ke wilayah Nusantara, bidang pemakaian bahasa Arab di Indonesia, dan kosakata bahasa Arab yang masuk ke dalam bahasa Indonesia.

Diambilnya bahasa Arab lebih dilatarbelakangi oleh sejumlah hal. Pertama, bahwa bahasa Arab memiliki jumlah penutur sebanyak 150 juta orang di seluruh dunia (Comrie via Montolalu, dkk, 2007). Kedua, bahasa Arab juga termasuk salah satu bahasa asing yang menyumbang kosakatanya ke dalam bahasa Indonesia. Ketiga, bahasa Arab berkaitan erat dengan seluk-beluk kehidupan keagamaan (Islam) yang dijalani oleh masyarakat Indonesia yang mayoritas pemeluk agama Islam. Ketiga alasan tadi 
merupakan faktor pendorong penulis untuk meneliti kembali perihal sejarah masuknya bahasa Arab ke wilayah Nusantara, bidang pemakaian bahasa Arab di Indonesia, dan kosakata bahasa Arab yang masuk ke dalam bahasa Indonesia.

Terkait itu, muncullah tiga masalah mendasar yang layak dikupas dalam konteks tulisan ini: (1) kapan sejarah masuknya bahasa Arab ke wilayah Nusantara?, (2) dalam bidang apa pemakaian bahasa Arab di Indonesia?, dan (3) apa-apa saja kosakata bahasa Arab yang masuk ke dalam bahasa Indonesia, khususnya yang tercatat di dalam Kamus Besar Bahasa Indonesia Pusat Bahasa Edisi Keempat (2008)? Kupasan ketiga masalah itu tertuang di bagian hasil dan pembahasan. Tulisan ini akan diakhiri simpulan yang relevan dengan ketiga masalah sebagaimana dituliskan tadi.

\section{Metode}

Metode penelitian yang digunakan adalah penelitian pustaka (library research). Menurut Suwandi (2013), penelitian kepustakaan adalah penelitian yang memfokuskan kegiatan penelitian melalui kajian kritis terhadap berbagai sumber pustaka. Sampel penelitian pustaka adalah sejumlah buku dan dokumen yang benar-benar dianalisis dalam penelitian ini untuk keperluan pengungkapan sejarah singkat, bidang pemakaian, dan kosakata bahasa Arab yang masuk ke dalam bahasa Indonesia.

Dengan mempertimbangkan kecukupan terhadap keseluruhan dokumen tentang sejarah singkat, bidang pemakaian, dan kosakata bahasa Arab yang masuk ke dalam bahasa Indonesia, maka sampel penelitian ini, antara lain, buku-buku dan kamus sebagai berikut: (1) Bahasa Indonesia untuk Ekonomi (1997) karya Soeparno, Suhardi, dan Haryadi, (2) Loan-words in Indonesian and Malay (2008) karya Russell Jones (ed.), dan (3) Kamus Besar Bahasa Indonesia Pusat Bahasa Edisi Keempat (2008) terbitan Pusat Bahasa bekerja sama dengan Penerbit Gramedia Pustaka Utama.

Teknik pengumpulan data yang dilakukan dalam penelitian ini adalah teknik pustaka dan dokumen. Sementara itu, teknik analisis yang digunakan adalah teknik analisis deskriptif yang meliputi tiga hal pokok, yaitu analisis kritis, analisis komparatif, dan analisis sintesis.

\section{Hasil dan Diskusi}

Di bagian ini penulis akan memaparkan hasil-hasil temuan tentang sejarah singkat, bidang pemakaian, dan kosakata bahasa Arab yang masuk ke dalam bahasa Indonesia. Temuan tersebut penulis bahas ke dalam tiga bagian, yaitu bagian pertama tentang sejarah singkat masuknya bahasa Arab ke Indonesia, bagian kedua tentang bidang pemakaian bahasa Arab di Indonesia, dan bagian ketiga tentang kosakata bahasa Arab yang masuk ke dalam bahasa Indonesia. Setiap bagian itu disertai data-data pendukung berupa foto/gambar, tabel, dan grafik yang relevan dengan pembahasan di bagian tersebut.

\section{Sejarah Singkat Masuknya Bahasa Arab ke Indonesia}

Arab merupakan nama bangsa di Jazirah Arab dan Timur Tengah. Bangsa itu memiliki bahasa yang disebut bahasa Arab atau bahasa Semit. Bangsa Arab sendiri terdiri atas Saudi Arabia, Suriah, Yordania, Irak, Mesir, dan sebagainya. Salah satu jenis pekerjaan yang dilakukan oleh bangsa Arab ialah menjadi pedagang. Hal itu dilukiskan dalam Alquran khususnya Surat Quraisy (106) ayat 1 dan 2: "Karena kebiasaan orang-orang Quraisy, (yaitu) kebiasaan mereka bepergian pada musim dingin dan musim panas."

Menurut keterangan Alquran terjemahan, orang-orang Quraisy biasa mengadakan perjalanan, terutama untuk berdagang ke negeri Syam (tanah Siria; negeri Siria) pada musim panas dan ke negeri Yaman pada musim dingin. Dalam perjalanan itu mereka mendapat jaminan keamanan dari penguasa negeri-negeri yang dilaluinya. Ini adalah suatu nikmat yang sangat besar dari Allah swt kepada mereka. Oleh karena itu, sewajarnyalah mereka menyembah Allah swt yang telah memberikan nikmat itu kepada mereka.

Dari hal di atas, kita pun mengetahui bahwa masuknya bahasa Arab ke Nusantara (sebutan negeri Indonesia pada saat itu) bersamaan dengan masuknya agama dan budaya Islam yang dibawa oleh para pedagang bangsa Arab, baik yang berasal dari Hadramaut maupun yang berasal dari Parsi, kurang lebih pada abad ke-14 (Jones, 2008: xxiii) atau akhir abad ke-15 (Soeparno, dkk, 1997). Dengan demikian, 
sembari berdagang, para pedagang bangsa Arab melakukan penyebaran agama dan budaya Islam kepada para pribumi (sebutan orang Indonesia pada saat itu).

\section{Bidang Pemakaian Bahasa Arab di Indonesia}

Bidang pemakaian bahasa Arab di Indonesia umumnya berkisar pada hal-hal yang berkaitan dengan bidang kehidupan umum dan keagamaan (Islam). Kosakata bahasa Indonesia yang berasal dari bahasa Arab untuk bidang kehidupan umum, antara lain, sahabat (sahābat), hakikat (haqīqat), ajaib ('ajā'ib), ilmu ('ilm), uzur ('uzr), simak (simā'), hadir (hāḍir), arif ('ārif), fakir (faqīr), fasih (fașìh), mafhum (mafhūm), gaib (gā'ib), hakim (hākim), islah (iṣlāh), sihir (sihr), masalah (mas'alah), kaidah

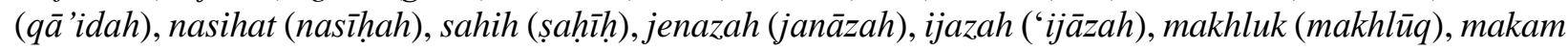
(maqām), mutlak (muțlaq), asas (asās), dan silsilah (silsilah).

Sementara itu, kosakata bahasa Indonesia yang berasal dari bahasa Arab untuk bidang kehidupan keagamaan (Islam), antara lain, mazhab (mażhab), umrah ('umrah), ikamah (iqāmah), khatib (khātib), rida (riḍa), zalim (z̄ālim), mukjizat (mu'jizat), rukuk (rukū'), fardu (farḍ), magfirah (magfirah), magrib (magrib), takwil (ta'wīl), makmum (ma'mūm), wudu (wuḍu'), tarikh (tārīkh), arasy ('arsy), syubhat (syubhāt), sujud (sujūd), takwa (taqwā), nahu (nahwu), haul (hawl), maulid (mawlid), inayah ('ināyah), ziarah (ziyārah), azan (ażān), ustaz (ustā̇̀), hafiz (hâafiz), takzim (ta'żìm), zalim (zāalim), akhirat ('ākhirah), maksiat (ma'siyyah), sunah, sunat (sunnah), dan surah, surat (sürah).

Banyaknya kosakata bahasa Arab yang dipakai dalam kehidupan umum dan keagamaan (Islam) di Indonesia menunjukkan, bahasa Arab memiliki pengaruh yang besar terhadap perkembangan bahasa Indonesia. Hal itu wajar, mengingat mayoritas penduduk di Indonesia memeluk agama Islam sehingga bahasa Arab dapat "merembes" ke dalam kehidupan umum dan keagamaan masyarakat Indonesia selama ini.

\section{Kosakata Bahasa Arab yang Masuk ke dalam Bahasa Indonesia}

Dalam Kamus Besar Bahasa Indonesia Pusat Bahasa Edisi Keempat (2008), terdapat label penggunaan bahasa yang menunjukkan dalam bahasa apa kata yang bersangkutan digunakan. Misalnya, bahasa Arab diberi label Ar pada lema atau kosakata yang tertera dalam kamus tersebut. Dalam bagian ini, penulis akan mengidentifikasi kosakata-kosakata bahasa Arab secara alfabetis - dari A hingga Z - yang masuk ke dalam bahasa Indonesia, khususnya Kamus Besar Bahasa Indonesia Pusat Bahasa Edisi Keempat (2008).

A

abadiah, abidin, abrar, abu, abyad, adabiah, adad, adalat, adnan, aglaf, ahadiat, ahlulbait, ahlulkitab, ahlulkubur, ahlunujum, ahlusuluk, ahlusunah, ahmar, ahsan, ainulyakin, ainunjariah, ajnabi, ajnas, akaid, akhwat, Akrab, akwal, al, alaihisalam, alaikasalam, alaikumsalam, alamah, alamatulhayat, alawar, alimiat, Aljalil, Alkabir, Alkadim, Alkadir, alkah, Alkasyaf, Allah, Allah azza wajalla, Allah subhanahu wa taala, Allahuma, almuazam, almukhlis, amanah, amirulhaj, amirulmukminin, anfas, anjar, anjir, anta, arbab, Asad, asali, asfal, asfar, aswad

B

baid, bait, bakdahu, baki, balad, bawab, bihi, bin, binti, bunduk, burkak

\section{D}

daayah, dahiat, dahriah, daim, dakaik, dakhil, dakik, dalal, dalalah, dalalat, damah, dar, darulaitam, darulakhirat, darulbaka, darulfana, daruljalal, dasin, Delu, din, dur, durat, dustur

$\mathbf{F}$

faal, fahrasat, fahsya, fakih, falah, falaj, farak, farik, farji, fasad, fasid, fatah, fikrah, fitri, fuad, fujur, fukaha, fukara, futur

G

gafar, gaffar, gafur, gamel, garar, gibah, gibtah, gulam, gurab ${ }^{1}$, gurab ${ }^{2}$, gurub, gurur, gusul, guyub

\section{$\mathbf{H}$}

habibi, habibullah, hablun, hadanah, hadas, hadirat ${ }^{1}$, hadirat ${ }^{2}$, hadirin, hadis, hafiz, hafizah, haik, haj, hajah, hajar, hajat, haji, hajib, hajim, hak, hakaik, hakam, hakim, hakulyakin, halakah, halal, halalbihalal, 
Hamal, hamba, hamdalah, hanif, harakah, harakat, hasad, hasan, hasib, hasud, haudah, haukalah, haul, haur, hawiah, hijir, himar, hokah, hudhud, hujah, hujaj, hukama, hukumullah, huriah, husnuzan, Hut

\section{I}

ibadah, ibadurahman, ibni, ibnu, ibra, ibtida, id, idah, Iduladha, Idulfitri, Idulkurban, ifah, Ifrit, iftar, iftitah, ihanah, ihdad, ihram, ihsan, ihtifal, ihwal, ijab, ijabah, ijajil, ijarah, ijas, ijmak, ijmal, ijtihad, ijtimaiah, ijtimak, ikab, ikamah, ikhtisar, ikhtilaf, ikhwan, ikhwanusafa, ikrab, ikram, iktibar, iktidal, iktikad, iktikaf, iktirad, iktiraf, ilafi, ilah ${ }^{1}$, ilah ${ }^{2}$, Ilahi, ilahiah, ilahiat, ilak, ilham, ilmu, imam, imamah, imamat, iman, imsak, inayat, insaf, insan, insya Allah, intifadah, inziaj, iqra, iradat, irafah, irsyad, Isa Almasih, isbat, isim, islah, Islam, isnad, isra, Isra Mikraj, israf, istianah, istiazah, istibra, istidlal, istidraj, istifham, istigasah, istigfar, istihadah, istihsan, istikamah, istikharah, istikhlaf, istiklal, istikmal, istima, istimaiah, istimna, istimtak, istinbat, istinja, istislah, istislam, istisna, istitaah, isya, istiak, itibak, itifak, itihad, itisal, iwad, izah

\section{$\mathbf{J}$}

jabal, Jabar, Jabariah, Jadi, jahil, jahiliah, jahiriah, jahul, jaiz, jalal, jali, jalil, jamak, jamal, jamiah, jamiatul hujaj, jamik, jamil, jamrah, janabah, janabijana, janah, janat, jani, jarab, jariah ${ }^{1}$, jariah ${ }^{2}$, jarimah, jasus, jazam, jazirah, jemaah, jenazah, jigrah, jihad, jilbab, jim, jimak, jin, jinayah, jisim, jizyah, jujah, Jumadilakhir, Jumadilawal, jumjumah, jumud, junub, juz.

\section{$\mathbf{K}$}

Kaabah, Kabil, kabir, kadahajat, Kadariah, kadim, kadim, kadir, kafaah, kafah, kafarat ${ }^{1}$, kafarat ${ }^{2}$, kafi, kafilah, kafir, kafir harbi, kafir muahid, kafir zimi, kafiri, kaftan, kahaf, kahin, kahrab, kahwaji, kaifiah, kaifiat, kaimat, kalimatullah, kalimatusyahadat, kalkalah, kamal, kamali, kamar, kamil, kanaah, kanisah, karahah, karbiah, karim, karimah, kasrah, kaswah, katib, kaul, khabis, khair, khali, khalifah, khalifatullah, Khalik, khalikah, Khalilkulalam, Khalikulbahri, khalil Allah, khalilullah, khamzab, khatam, khatib, khatimah, khauf, Khawarij, khawas, khawasulkhawas, khiar, khidaah, khidmah, khidmat, khilaf, khilafiah, khinzir, khisit, khitah, khitan, khitbah, khizanatulkitab, khotbah, khuduk, khulafa, khulafaurrasyudin, khuldi, khulki, khuluk, khurafat, khusyuk, kiam, kidam, kitab, kitabullah, kufu, kufur, kulub, kulzum, kunut, kurban, kurma, kutubusitah, kuud

\section{$\mathbf{L}$}

labuda, lagiah, laknatullah, latif, lawazim, lian, logawiah, loh mahfuz

\section{M}

maab, mabrur, mafrusat, mafsadah, magfirah, magrur, mahbub, mahbubah, mahfuz, mahmud, mahram, mahsyar, mahzurat, maimun, mairat, maisir, majenun, makbud, makbul, makdan, makhdum, makhraj, makiyah, maklaf, makmal, makramat, makruf, makruh, maksum, maktab, makul, makulat, malakat, malakut, malik, Maliki, Malikuljabar, Malikulmuluk, malim, malka, malun, mamduhah, mamlakat, manasik, mandil, mansukh, mantiki, mantuk, manzil, manzilah, 192 mardud, marhaban, marjik, masjid, Masjidilaksa, Masjidilharam, maskanat, maslahat, masuliah, masya Allah, masyakah, masyhadat, mauziah, maujudat, maukif, maukuf, maula, maulana, maulhayat, maulid, maulidulrasul, mauz, mawadah, mazhab, mazi, mikat, mikraj, mim, Mina, minhaj, mintak, mintakulburuj, misbah, mistar, miswat, mizab, mualaf $^{\prime}$, mualaf ${ }^{2}$, mualamat, mualif, mualim, muamalah, muamalat, muanas, muarikh, muasasah, muasir, muazam, muazin, mubah, mubalig, mubaligah, mubarak, mubarat, mubazir, mubtadi, mudarabah, mudarat, mudarib, mudasir, mudat, mufaham, mufakat, mufarik, mufasal, mufasir, muflis, mufrad, mufsidin, mufti, mugabat, muhabah, muhadarah, muhadat, muhajat, muhajir, muhajirin, muhal, muhalil, muhami, Muhammad, Muharam, muhasabah, muhdas, muhib, muhibah, muhit, muhlikah, muhrim, muhrim ${ }^{2}$, muhsanah, muhsin, muhtasyam, mujadalah, mujadid, mujahadat, mujahid, mujahidin, mujarad, mujbir, mujtahid, mujtamak, mukadas, 89 mukadim, mukadis, mukalaf, mukalid, mukaram, mukatabah, mukena, mukharabah, mukhalaf, mukhalif, mukhalis, mukhlis, mukhtasar, mukim, mukimin, mukjizat, mukmin, mukminat, mukminin, muktabar, muktamad, muktamar, muktamirin, muktazilah, mulazamah, mulhid, multazam, muluk, mumayiz, munafik, munafikin, munajat, munajim, munakahat, munasabah, munazara, murabahah, murad, murakab, mursal, mursyid, murtad, Musa, musaadah, musabab, musabaqah, musafir, musafirin, musakat, musala, musaqat, mushaf, muslih, muslim, muslimat, muslimin, mustahak, mustahik, mustaid, mustajab, mustakim, mustamik, Mustari, musyarakah, musyarakat, musyarik, musyawarah, musyrik, musyrikin, musytak, mutaakhirin, mutah, mutakalim, mutaki, mutalaah, 
mutasawif, mutawif, muwahid, muwajahah, muwakal, muwakil, muzah, muzakar, muzakarah, muzaki, muzakir, muzamil, muzaraah, muzawir

$\mathbf{N}$

naam, nabaun, nafar, nahi, najis, nasar, nasihat, nasyid, nawaitu, nazar, nazim, nusyu, nuzul, Nuzululquran

Q

qada ${ }^{1}, q a d a^{2}$, qaf, qanun, qari, qariah, qasar, qiamulail, qiraah, qudrah, qudsi, qurah, Quran, qurani

\section{$\mathbf{R}$}

ra, rabana, rabani, rabi, Rabiulakhir, Rabiulawal, Rabulizat, rafik, rahim, rahimakallah, rahimakumullah, rahman, rahmat, rahmatullah, rai, Rajab, rajabiah, rakaat, Ramadan, rasul, Rasulullah, rasyid, rasywah, ratib, raudatulatfal, ria, riadat, rial, ribatat, ridi, rijal, rijalulgaib, risalah, rukhsah, rukiah, rukuk, rukyat, rukyatulhilal

$\mathbf{S}$

saadah, saadin, sabah, sabar, sabil, sad, sadir, safa, Safar ${ }^{1}$, safar ${ }^{2}$, safsaf, sahib, sahibulbait, sahibulhajat, sahibulhikayat, sahibulmal, sahifah, sahih, sahir, sahur, sai, saif, sair, sajadah, sakar, sakhawat, sakhi, sakhrat, sakhsi, salaf, salam, salat, salatin, Saleh, salik, salim, samaniah, sanad, sanat, sanawiah, saraf, satar, saum, Saur, sawab ${ }^{1}, s w_{a b}{ }^{2}$, sayidi, sayidina, selawat, setan, siam, sidik, Sidratulmuntaha, sifatullah, sir, sirat, siratalmustakim, siti, subhana, sufrah, suhuf, sulalah, sulbi, sumah, sunah, sunat, sunatullah, Sunbulat, surah, surahi, suuladab, suuzan, syabah, Syaban, syafaat, syafakat, Syafii, syahadat, syahadatain, syahda, syahdan, syahdu, syahid, syahriah, syahsiah, syajarah, syajarkhuldi, syakhsi, syamsi, syamsiah, syamsu, syar, syarah, syariat, syarif, syarifah, Syawal, syekh, syiar, syin, syirik, syubhat, syukur, syumuliah, syur, syura, syuriah, syuruk

\section{$\mathbf{T}$}

taala, taaruf, taasub, taat, taazur, tabarak, tabaruk, tabayun ${ }^{l}$, tabayun ${ }^{2}$, tabii, tabiin, tadabur, tadaruk, tadarus, tadbir, tadwin, tafadal, tafahus, tahajud, 30 tahalul, taharah, tahiat, tahir, tahkim, tahlil, tahmid, tahniah, tahnik, taib, tajali, tajarud, tajdid, tajriah, takabur, takarir, takarub, takbir ${ }^{l}$, takbir ${ }^{2}$, takbiratulihram, takdir, takdis, takhlik, takhsis, takjil, taklid, taklif, taklikat, taklim, takmir, takrif, takrim, taksir, takwa, takwil, takwim, takwin, takyin, takziah, takzim, takzir, talak, talaki, talbiah, talib, tamatulkalam, tamyiz, tanbiat, tanfiziah, tanwin, tanwir, tanzil, Tarawih, tarbiah, tarjih, tartil, tasamuh ${ }^{l}$, tasamuh ${ }^{2}$, tasaruf, tasawuf, tasbih, tashih, taslim, tasmik, taswir, tasyahud, tasyakur, tasyayuh, tasydid, tasyhid, tasyrih, tasyrik, taufah, taufik, tauhid, tauhidiah, tauliah, taun, Taurat, tausiah, tawadu, tawaduk, tawaf, tawaf qudum, tawaf wada, tawajuh, tawakal, tawaruk, tawasul, tawasut, tawazun, tayamum, tayib, tayibah, tazkirah, tilawah, tufah, tuhfah, tuhfahtulajnas, tuhmah

\section{$\mathbf{U}$}

ubudiah, ujub, ukhrawi, ukhuwah, uktab, um, umara, umi ${ }^{1}$, umi ${ }^{2}$, umrah, urian, ustaz, ustazah, usur, uswah, Utarid, uzlah

\section{W}

waad, waadat, wabakdu, wabakdu kalam, wabarakatuh, wadi, wafa ${ }^{1}$, wafa ${ }^{2}$, wafak, wahdah, wahdaniah, wahdiah, wahib, wahid, wahyu, waid, waima, wakaf, wakalah, walad, walakhir, wali Allah, wali hakim, wali mujbir, walimah, waliullah, wallahualam, warak, warid, wasak, wasal, wasalam, Wasi ${ }^{l}$, wasi ${ }^{2}$, wasilah, wasitah, watan, wijdaniah, wikalat, wiladah, wudu, wujud, wukuf

\section{$\mathbf{Y}$}

yad, Yahudi, yakin, Yakjuj wa Makjuj, yaum, yaumudin, yaumulbarzah, yaumulhisab, yaumulmizan, yaumulakhir, yaumuljamak, yaumuljaza, yaumulkiamah, yaumulmakhsyar

\section{$\mathbf{Z}$}

zabah, Zabaniah, zabarjad, zabhah, zabib, Zabur, zahid, zaim, zaitun, zakar, zakat, zakat fitrah, zakat mal, zakiah, zakirah, zakum, zal, zalim, zaman, zamzam, zan, zat, zawiat, ziadah, ziarah, zikir, zikir amali, zikir kalbu, zikrul maut, zilullah, zina, zindik, zirnikh, Zohal, Zohrah, zuama, zuhud, zuhudiah, zuhur, zulfikar, Zulhijah, Zulkaidah, zulmat, zuriah 


\section{Simpulan}

Berdasarkan uraian di atas, maka penulis dapat mengambil sejumlah simpulan sebagai berikut; Dari faktor sejarah, masuknya bahasa Arab bersamaan dengan masuknya budaya dan agama Islam yang dibawa oleh para pedagang bangsa Arab, baik yang berasal dari Hadramaut maupun yang berasal dari Parsi, kurang lebih pada abad ke-14 atau akhir abad ke-15.

Bidang pemakaian bahasa Arab di Indonesia kebanyakan berkisar pada hal-hal yang berkaitan erat dengan kehidupan keagamaan (Islam) dan kehidupan umum. Hal itu dapat dimengerti karena Indonesia merupakan negara dengan mayoritas penduduk memeluk agama Islam.

Kosakata bahasa Arab yang masuk ke dalam bahasa Indonesia, khususnya yang tercatat dalam Kamus Besar Bahasa Indonesia Pusat Bahasa Edisi Keempat (2008) mencapai angka 1.097 buah, yang mencakup bidang keagamaan (Islam) dan bidang kehidupan umum.

\section{Ucapan Terima Kasih}

Terima kasih kepada semua pihak yang membantu penulis dalam menyelesaikan artikel hasil riset ini sehingga bisa diterbitkan di Jurnal Hortatori.

\section{Daftar Rujukan}

Chaer, A. Telaah bibliografi kebahasaan bahasa Indonesia/melayu. Jakarta: Penerbit Rineka Cipta, 2010. Print.

Jones, R. (ed). Loan-words in Indonesian and Malay. Jakarta: Yayasan Obor Indonesia bekerja sama KITLV-Jakarta, 2008. Print.

Montolalu, L.R., dkk. "Tipologi Bahasa dan Bahasa-bahasa di Dunia" dalam Kushartanti, dkk (peny.). Pesona Bahasa: Langkah Awal Memahami Linguistik. Jakarta: PT Gramedia Pustaka Utama, 2007. Print.

Pusat Bahasa. Kamus besar bahasa Indonesia pusat bahasa edisi keempat. Jakarta: Penerbit PT Gramedia Pustaka Utama, 2008. Print.

Soeparno, H. dan Suhardi. Bahasa Indonesia untuk ekonomi. Yogyakarta: Penerbit Ekonisia, 1997. Print.

Suwandi, S. "Pengembangan Bahan Ajar Mata Pelajaran Bahasa Indonesia Berbasis Kompetensi”, Jurnal Wacana Bahasa dan Sastra, Vol. 11, No. 1, April (2013), hlm. 1-10. Print.

Tadmor, U. "Kontroversi Asal-usul Bahasa Melayu-Indonesia" dalam Yassir Nasanius (peny.). PELLBA 18. Jakarta: Yayasan Obor Indonesia bekerja sama dengan Pusat Kajian Bahasa dan Budaya Unika Atma Jaya Jakarta, 2007. Print. 